\title{
Use of Online Conductivity Monitoring to Study Sodium Mass Balance in Chronic Haemodialysis Patients: Prospects for Treatment Individualisation
}

\author{
Aghogho Odudu a Stewart Lambie ${ }^{a}$ Maarten W. Taal ${ }^{\mathrm{a}}$ Richard J. Fluck \\ Christopher W. McIntyre ${ }^{a, b}$

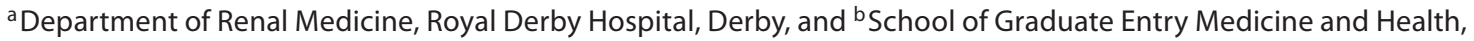 \\ University of Nottingham, Nottingham, UK
}

\section{Key Words}

Online conductivity monitoring · Sodium mass balance .

Chronic haemodialysis patients

\begin{abstract}
Background: Failure to achieve isonatric haemodialysis (HD) drives an expansion of extracellular volume leading to increased interdialytic weight gain (IDWG). This may be a causative factor in the development of HD-induced cardiac injury. We examined total and diffusive sodium mass balance during HD. Methods: 24 chronic HD patients using a fixed $140 \mathrm{mmol} / \mathrm{l}$ sodium concentration were studied over 4 weeks. Dialysate and plasma conductivity and ionic mass balance (IMB) were recorded. IMB estimates total ionic transfer across the HD membrane. Results: Mean total IMB was $338 \mathrm{mmol}$ indicating net sodium removal. Intrapatient variability was less than interpatient variability (coefficient of variation $=42$ vs. $26 \%$, respectively). The diffusive component of ionic mass balance $\left(\mathrm{IMB}_{\text {diff }}\right)$ was $97 \pm 18 \mathrm{mmol}$ approximating $29 \%$ ( $\pm 22-36$ ) of total sodium removal. IMB ${ }_{\text {diff }}$ also correlated with both plasma conductivity and predialysis plasma sodium ( $r^{2}=0.82$ and 0.6 , respectively; $\left.p<0.0001\right)$ as well as the reduction in plasma conductivity and plasma sodium during $\mathrm{HD}\left(\mathrm{r}^{2}=0.7\right.$ and 0.5 , respectively; $\left.\mathrm{p}<0.0001\right)$.
\end{abstract}

Conclusion: HD against a fixed dialysate sodium concentration of $140 \mathrm{mmol} / \mathrm{I}$ results in a wide range of sodium removal with a mean of $29 \%$ removed by diffusion. Online conductivity monitoring can be utilized as part of a variety of strategies to enable the delivery of individualised and isonatric HD. Further study is required to explore the utility of such strategies which may be crucial in reducing IDWG and HD-induced cardiac injury.

Copyright $\odot 2011$ S. Karger AG, Basel

\section{Introduction}

It is well recognised that haemodialysis (HD) patients suffer excess cardiovascular morbidity and mortality [1]. It is also becoming appreciated that this rate of cardiovascular attrition is not driven by the same variety of traditional risk factors or pathophysiological processes that are important in the general population [2]. There is growing evidence focusing on the mechanisms underpinning this excess cardiac mortality including HD-induced cardiac injury [3]. The historical focus on small solute clearance precipitated by the NCDS study, improvements in HD technology and economic factors have driven an inexorable pressure to reduce treatment times

\section{KARGER}

Fax +4161306 1234 E-Mail karger@karger.ch www.karger.com

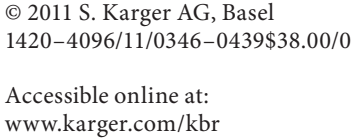

Dr. C.W. McIntyre

Department of Renal Medicine

Royal Derby Hospital

Uttoxeter Road, Derby DE22 3NE (UK)

Tel. +44 1332789 344, E-Mail Chris.McIntyre@nottingham.ac.uk 
$[4,5]$. This has promoted a reliance on higher dialysate sodium concentrations from 130 to $145 \mathrm{mmol} / \mathrm{l}$ or more as this is thought to reduce adverse intradialytic symptoms and haemodynamics associated with shorter treatment times [6]. However, truly adequate dialysis should be isonatric allowing for complete removal of the interdialytic sodium gain and avoiding intradialytic sodium loading and consequently higher interdialytic weight gain (IDWG) [7]. Increased IDWG or increased ultrafiltration volumes are associated with increased blood pressure (BP), left ventricular mass and mortality [8-11]. Furthermore, we have identified ultrafiltration volume as a potent and modifiable determinant of HD-induced myocardial stunning and this may be an integrating factor linking IDWG to excess mortality [12]. The terminology of 'high' and 'low' dialysate sodium concentrations can be unclear. Only the ionized proportion of sodium is available for diffusion, hence its movement is determined by the gradient between the concentrations of non-complexed, electrochemically active ions from plasma to dialysate as well as temperature and acidity. The GibbsDonnan effect refers to a phenomenon caused by anionic plasma proteins too large to traverse the dialysis membrane, creating an electric field that attracts cations and reducing the amount of plasma diffusible sodium [13]. This results in a hypotonic ultrafiltrate and allows the movement of sodium and water to become uncoupled during HD [14]. This makes it possible for patients to load sodium during dialysis, despite dialysate sodium concentration being lower than the predialysis plasma sodium concentration (commonly termed 'low' dialysate sodium concentration) $[15,16]$. More recently, the non-osmotic storage of sodium in skin and other tissues has been described and this may further allow dissociation of sodium and water handling [17]. Though the effects of this may be negligible over a single HD session, the potential of this reservoir of sodium ions to buffer sodium transport over a longer period and influence BP and IDWG has not been fully elucidated. The picture is complicated further by the methods of measuring sodium. Laboratories typically use flame spectrophotometry or indirect potentiometry with diluted samples to measure total sodium concentration, which is practical for multiple samples. This is typically $4-6 \%$ lower than the electrochemical activity of ionised sodium in plasma water measured directly with an ion-selective electrode [18].

This has culminated in a situation where the goal of an individualised isonatric HD prescription has been hampered by the lack of effective and simple tools to study the consequences of dialysate sodium concentration to so- dium mass balance in routine clinical practice. Such choices have been largely based on empirical observation. Recent study into the use of online monitoring of plasma conductivity has demonstrated that such technology is capable of accurately estimating sodium mass balance during HD [19-21]. This study aimed to explore the use of online conductivity monitoring and the measurement of ionic mass balance (IMB), to examine sodium removal and the relationships with plasma conductivity, in chronic HD patients. Furthermore, we set out to study the degree of variability in sodium removal (both within individuals and between patients) in an effort to define how this technology might assist in the development of individualised dialysate sodium prescriptions to allow isonatric dialysis.

\section{Methods}

\section{Patients}

We prospectively studied 24 (21 male, 3 female) stable chronic HD patients for a 4 -week period ( 288 treatments in total). Demographics are summarised in table 1 . All had a well-functioning native arteriovenous fistula and were dialysed in a discrete low dependency unit. Patients with diabetes were excluded as there are data suggesting that assessment of sodium mass balance would be significantly confounded by glycaemic control [22]. Upon entry to the study, patients had their dry weight confirmed with reference to clinical examination and serial BP readings. A standard low-sodium diet ( $<6 \mathrm{~g}$ per day) was reinforced, but no additional dietary interventions or assessments were performed. Ten patients were oliguric (defined as urine output of 10-150 ml/ day), whilst 14 patients were anuric (defined as urine output less than $10 \mathrm{ml} /$ day). For the purposes of this study, we assumed that these patients had no significant residual renal function. The study was approved by the Derbyshire Research Ethics Committee and all patients gave informed consent (table 1).

\section{HD Schedule}

HD was performed using Integra ${ }^{\circledR}$ dialysis monitors equipped with Diascan ${ }^{\circledR}$ conductivity and Hemoscan ${ }^{\circledR}$ haemoglobin concentration monitoring modules (Gambro Hospal, Mirandola, Italy). All patients had 4-hour treatment sessions, 3 times per week using haemophan dialysers (Hospal HG 500-700). Dialysate composition (in $\mathrm{mmol} / \mathrm{l}$ ) was: sodium 140 , bicarbonate 32 , potassium 1, calcium 1.25, magnesium 0.5 , chloride 107.5 , glucose 5.6 and acetate 3 . Dialysate sodium concentration was measured by flame photospectometry (using an aqueous calibrant) and calibrated against dialysate inlet conductivity. Dialysate inlet conductivity is constrained to no more than $1 \%$ drift before automated recalibration (Hospal supplied data) and lack of significant drift was confirmed by review of the recordings of dialysate conductivity for each of the studied treatments. In addition, the dialysis monitor automatically calibrates the conductivity cells against reverse osmosis water at the start of each session. The internal conductivity cells were also calibrated according to the 
Table 1. Demographics of study patients $(n=24)$

\begin{tabular}{lc} 
Mean age \pm SD, years & $62 \pm 16$ \\
Mean length of time on dialysis \pm SD, months & $14.8 \pm 14.5$ \\
Mean baseline serum sodium \pm SD, mmol/l & $138.8 \pm 3.5$ \\
Characteristic & \\
$\quad$ Male:female & $21: 3$ \\
$\quad$ Non-smoker:current smoker & $23: 1$ \\
$\quad$ History of ischaemic heart disease & 2 \\
Ethnicity & \\
$\quad$ Caucasian:Afro-Caribbean & $23: 1$ \\
Causes of end-stage renal disease & \\
$\quad$ Glomerulonephritis & 5 \\
IgA nephropathy & 4 \\
Renovascular disease & 3 \\
Focal and segmental glomerulosclerosis & 2 \\
Polycystic kidney disease & 2 \\
Reflux nephropathy & 2 \\
Hypertensive nephrosclerosis & 1 \\
Obstructive uropathy & 1 \\
Cause unknown (small kidneys) & 3 \\
Number of BP medications prescribed & \\
0 & 7 \\
1 & 2 \\
2 & 11 \\
3 & 4 \\
\hline
\end{tabular}

manufacturer's instructions against reverse osmosis water and a solution of known concentration using a conductivity meter (IBP HDM97BN, Hanover, Germany). Dialysate temperature was $37.0^{\circ} \mathrm{C}$, dialysate flow was $500 \mathrm{ml} / \mathrm{min}$, and blood flow was 250 $410 \mathrm{ml} / \mathrm{min}$. Anticoagulation was by unfractionated heparin. For each session, net fluid removal was set on an individual basis according to ideal dry weight. No patients underwent sodium or ultrafiltration profiling. Dialysis prescriptions were held on a separate server and downloaded to the patient's dialysis monitor for each treatment. All data were uploaded to patient-specific files at the end of each treatment for subsequent analysis. Manually recorded data included pre- and postdialysis weight, systolic, diastolic and mean arterial BP at 15-min intervals. Intradialytic hypotension was defined as an absolute systolic BP $<90 \mathrm{~mm} \mathrm{Hg}$ or $>30 \%$ decrease in systolic BP from the predialysis value or any fall in $\mathrm{BP}$ requiring intervention.

\section{Assessments of Sodium Mass Balance}

Sodium mass balance was estimated by non-invasive, online conductivity monitoring using the Diascan module and ionic dialysance measurements. Based on the theory developed by Polaschegg [23], this system utilises temperature-compensated conductivity probes at both the dialysate inlet and waste dialysate outlet. Dialysate inlet conductivity is transiently increased by about $1 \mathrm{mS} / \mathrm{cm}$ for $2 \mathrm{~min}$ intermittently throughout the HD session (every $30 \mathrm{~min}$ ). Measurement of the difference between inlet and outlet conductivity before and after transient increase allows ionic dialysance and effective plasma conductivity to be derived (and continuously displayed on the dialysis monitor) according to formulae detailed in the online supplementary appendix 1 (www. karger.com/doi/10.1159/000329355). The relative contributions of diffusion $\left(\mathrm{IMB}_{\text {diff }}\right)$ and convection to sodium mass balance were estimated according to formulae also detailed in the online supplementary appendix 1 . Pre- and postdialysis plasma sodium was sampled once per week during the study period and measured using an indirect ion-selective electrode-based method (interbatch assay coefficient of variation $=0.58-1 \%$ ).

\section{Statistical Analysis}

IDWG is expressed as a percentage of dry weight. All data were analysed using GraphPad Prism version 4.0 for Windows (GraphPad Software, San Diego, Calif., USA). Correlation plots were subsequently analysed by linear regression. Coefficient of determination was calculated from the Pearson correlation or Spearman's rank-order correlation depending on normality. Intrapatient variability was assessed by calculation of the coefficient of variation. Data are expressed as mean \pm SEM (95\% confidence intervals) unless otherwise stated.

\section{Results}

Validation of our estimate for $\mathrm{IMB}_{\text {diff }}$ derivation for 5 randomly selected patients was shown with an approximately linear fall $\left(\mathrm{r}^{2}=0.89\right.$; fig. S1, see online suppl. appendix 1). With respect to the data in all 24 patients and 288 treatments, there were no episodes of intradialytic hypotension throughout the study period. All patients had net sodium removal during HD with a total IMB of $338 \pm 9.4 \mathrm{mmol}$ (range, 320-357). The component of sodium mass balance attributable to diffusion $\left(\mathrm{IMB}_{\text {diff }}\right)$ was $97.1 \pm 18.2 \mathrm{mmol}$ (range, 61.3-133.2). The relative contribution of diffusion to total IMB was a mean of $29 \%$ ( $\pm 22-36)$. Three of the 24 patients experienced negative $\mathrm{IMB}_{\text {diff, }}$ indicative of a positive dialysate to plasma concentration gradient, resulting in net diffusion of sodium from dialysate into the patient (fig. 1). There was considerable variation in the degree of apparent sodium removal during an HD session between individual patients. Total IMB per session varied widely from 96 to $515 \mathrm{mmol}$ between subjects but the variation within individuals was lower (coefficient of variation $=42$ vs. $26 \%$, respectively). Mean ultrafiltration volume was $1.85 \pm 0.05 \mathrm{~kg}$ (range, $1.74-1.96)$. $\mathrm{IMB}_{\text {diff }}$ was highly correlated with both plasma conductivity and plasma sodium concentration at the start of $\mathrm{HD}\left(\mathrm{r}^{2}=0.82\right.$ and 0.6 , respectively; $\mathrm{p}<0.0001$; fig. 2). $\mathrm{IMB}_{\text {diff }}$ was also correlated with the reduction in plasma conductivity and plasma sodium during $\mathrm{HD}$ $\left(\mathrm{r}^{2}=0.7\right.$ and 0.5 , respectively; $\mathrm{p}<0.0001$; fig. 3$)$. Plasma conductivity fell from a mean of $14.16 \pm 0.02 \mathrm{mS} / \mathrm{cm}$ (range, $14.12-14.20$ ) to $13.76 \pm 0.01 \mathrm{mS} / \mathrm{cm}$ (range, $13.74-$ 13.78) ( $\mathrm{p}<0.0001)$. Plasma sodium concentration fell 

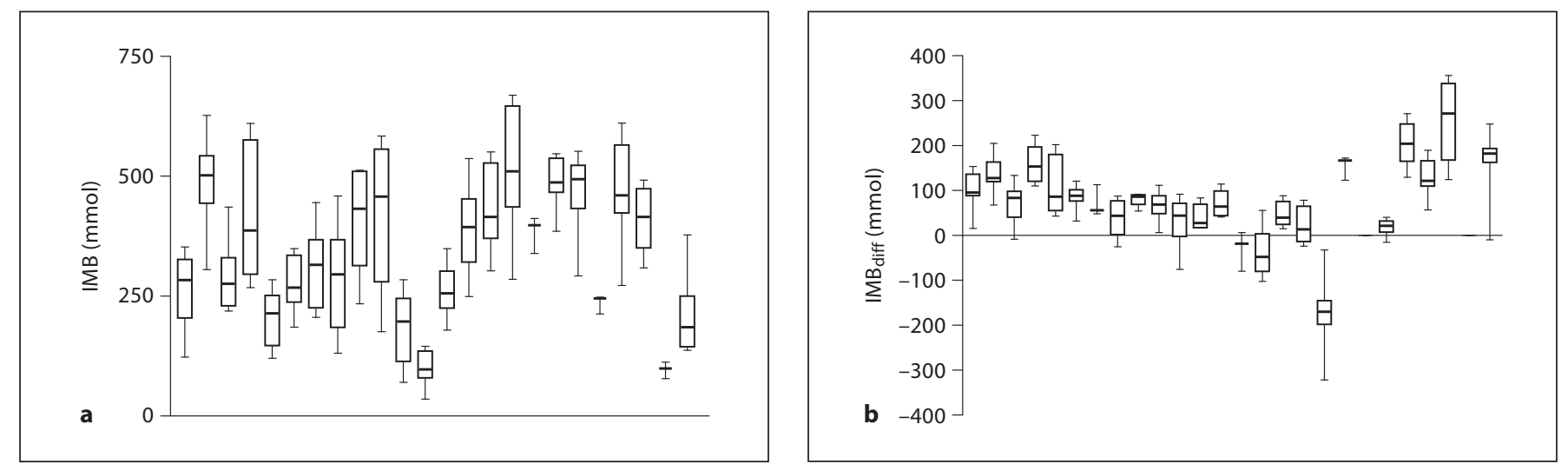

Fig. 1. Inter- and intrapatient variation in total $\operatorname{IMB}(\mathbf{a})$ and $\operatorname{IMB}_{\text {diff }}(\mathbf{b})$ over the study period in 24 patients.
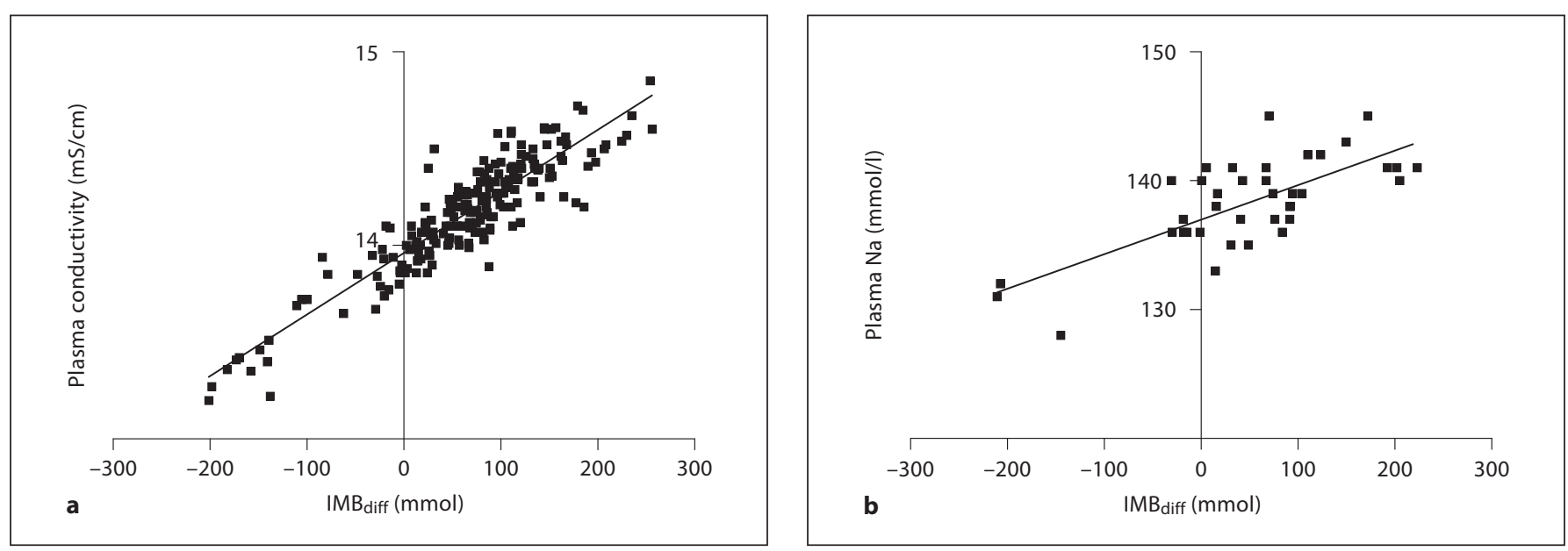

Fig. 2. Relationship between $\mathrm{IMB}_{\text {diff }}$ and plasma conductivity at the start of $\mathrm{HD}\left(\mathrm{r}^{2}=0.82\right)(\mathbf{a})$ and plasma sodium concentration at the start of $\mathrm{HD}\left(\mathrm{r}^{2}=0.6\right)(\mathbf{b}) . \mathrm{p}<0.0001$.

Table 2. Correlations of IMB and $\mathrm{IMB}_{\text {diff }}$ to IDWG and BP

\begin{tabular}{lrrrrrr}
\hline Parameter & Mean & SEM & $\begin{array}{l}\text { Corre- } \\
\text { lation } \\
\text { to IMB }\end{array}$ & $\begin{array}{l}\mathrm{p} \\
\text { value }\end{array}$ & $\begin{array}{l}\text { Corre- } \\
\text { lation } \\
\text { to IMB }\end{array}$ & $\begin{array}{l}\mathrm{p} \\
\text { valf }\end{array}$ \\
\hline HD MAP, mm Hg \\
$\quad$ Before & 101.9 & 1.4 & -0.06 & 0.45 & -0.06 & 0.48 \\
$\quad$ After & 101.4 & 5.2 & 0.03 & 0.73 & -0.04 & 0.61 \\
IDWG, kg & 1.9 & 0.11 & 0.57 & $<0.01$ & 0.62 & $<0.01$ \\
IDWG/DW, \% & 2.8 & 0.06 & 0.77 & $<0.01$ & 0.81 & $<0.01$ \\
\hline
\end{tabular}

Spearman's coefficient. MAP $=$ Mean arterial pressure. IDWG/DW refers to IDWG as a percentage of dry weight. from $138.8 \pm 0.43 \mathrm{mmol} / \mathrm{l}$ (range, 137.9-139.7) to 134.8 $\pm 0.28 \mathrm{mmol} / \mathrm{l}$ (range, $134.8-136$ ). Only 3 patients received treatments over the study period that resulted in an increase in plasma conductivity and sodium concentration. They had negative $\mathrm{IMB}_{\text {diff }}$ values, reflecting a positive dialysate to plasma sodium concentration gradient. Plasma sodium measurements correlated well with plasma conductivity measured by ionic dialysance (fig. 4).

There was no significant association of IMB with systolic, mean or diastolic BP either before or after dialysis. There was a significant correlation of IMB and $\mathrm{IMB}_{\text {diff }}$ with IDWG, whether expressed in absolute terms or relative to dry weight (table 2). 

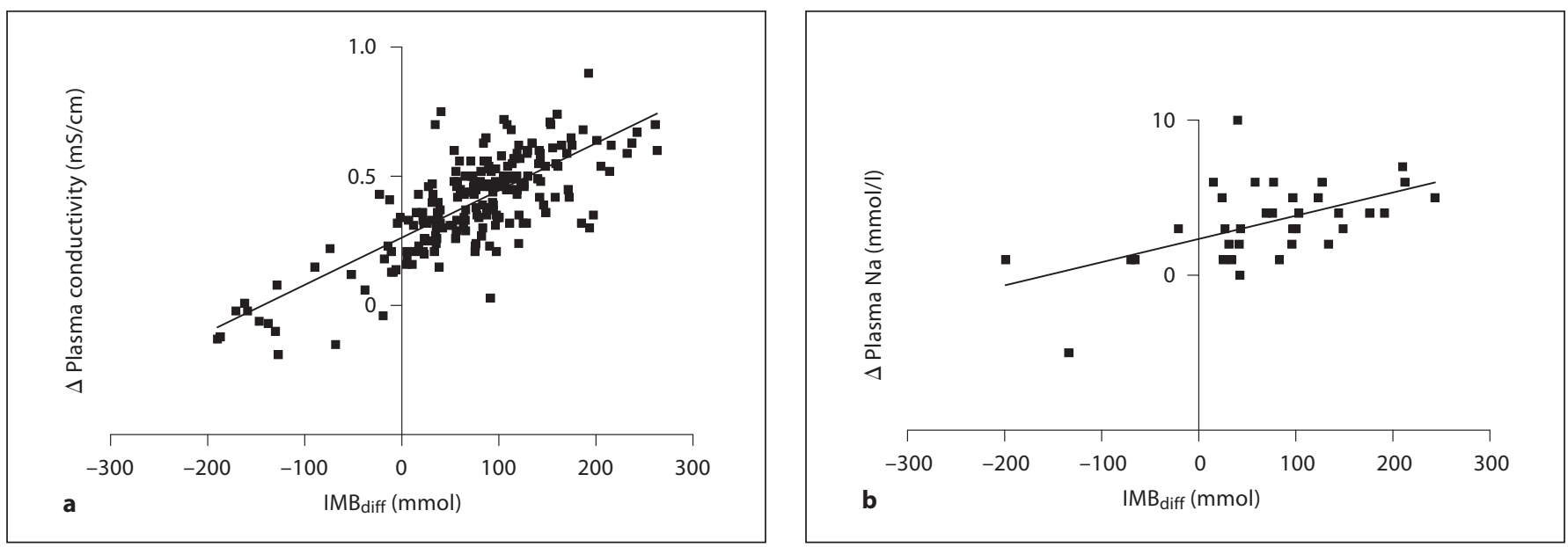

Fig. 3. Relationship between $\mathrm{IMB}_{\text {diff }}$ and $\Delta$ plasma conductivity from start to finish of $\mathrm{HD}\left(\mathrm{r}^{2}=0.7\right)$ (a) and $\Delta$ plasma sodium concentration $\left(\mathrm{r}^{2}=0.5\right)(\mathbf{b}) . \mathrm{p}<0.0001$.

There were no significant associations of IMB with total reductions in relative blood volume or intradialytic hypotensive episodes. We divided the data into after weekend days (Monday and Tuesday) against the other days and found no significant differences for all variables of interest including IDWG, pre- and post-dialysis plas$\mathrm{ma}[\mathrm{Na}], \mathrm{IMB}$, and all components of $\mathrm{BP}$ (non-parametric Wilcoxon test).

\section{Discussion}

The aim of this study was to further evaluate the use of online conductivity monitoring to study sodium mass balance in chronic HD patients. The resultant data can best be divided into three separate, but interrelated strands. Firstly, we have demonstrated a high degree of between-patient variability in a surrogate marker of sodium mass balance (IMB) in contrast to a low degree of within-patient variability. Such a finding suggests that individualised dialysate sodium concentration would be both desirable and possible. Secondly, we have confirmed the importance of predialysis plasma sodium concentration in influencing diffusive sodium movements. Thirdly, we have demonstrated a relationship between diffusive sodium movement and the difference in plasma conductivity observed over a given HD treatment session. This may have implications for the prescription of a specific amount of desirable sodium removal. Measurement of IMB confirmed at least some sodium removal in all

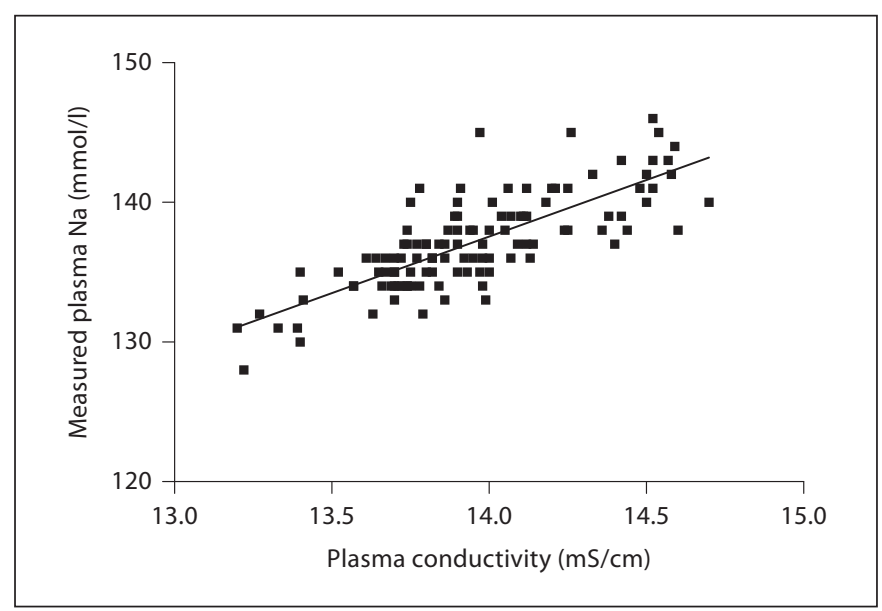

Fig. 4. Relationship between plasma conductivity and plasma sodium measurements $\left(\mathrm{r}^{2}=0.6\right)$. $\mathrm{p}<0.0001$.

patients. The level of removal was highly variable between patients. When considering $\mathrm{IMB}_{\text {diff }}$, the same pattern of variability was noted; however, 3 out of 24 patients had values suggesting net movement of sodium into their circulation. This level of variability has not been directly observed previously. A 2002 study by Moret et al. [21] demonstrated far less pronounced variability in IMB. This was a 13-patient study with a significant proportion having $\mathrm{HD}$ twice per week, with treatment times ranging from 180 to $270 \mathrm{~min}$. Seven of the 13 patients had significant residual renal function and the contribution of 
this to sodium mass balance was not quantified. We observed interpatient variability in IMB nearly twice as large as within patient. This is consistent with reported observed interpatient variability in plasma sodium concentrations. Gotch et al. [24] studied predialysis plasma sodium concentrations over a protracted period. Plasma sodium concentration varied from 132 to $144 \mathrm{mmol} / \mathrm{l}$ between patients, but varied by less than $2 \mathrm{mmol} / \mathrm{l}$ within individual patients. The stability of this set point and its relation to IDWG and hypertension has more recently been confirmed $[25,26]$. This further supports a rationale for individualisation of the dialysate sodium prescription [27].

The distinction between sodium mass balance attributable to convection with ultrafiltration and by diffusive processes has been subject to further study, both in terms of theoretical modelling and observation. Mathematical predictions of sodium mass balance in a two-compartment model with dialysate sodium of $140 \mathrm{mmol} / \mathrm{l}$ estimate that diffusion contributes around $30 \mathrm{mmol}$ of sodium removal in a $60-\mathrm{kg}$ individual [28]. Both the overall values and relative contributions to total sodium removal, available from diffusion, are consistent with our data. Moret et al. [21] also used IMB measurement to study sodium removal using a variety of dialysate sodium concentrations (including $140 \mathrm{mmol} / \mathrm{l}$ ). In this study, the patients were initially dialysed without ultrafiltration for $1 \mathrm{~h}$ during which they found a mean removal of around $30 \mathrm{mmol}$. It is difficult to use these data to estimate the contribution of diffusion to sodium mass balance over a 4-hour dialysis session as the second period of ultrafiltration was not assessed, but even a crude assumption of a linear rate of removal approximates to $120 \mathrm{mmol}$. This is of the same order as our estimate of a mean of $97 \mathrm{mmol}$ for $\mathrm{IMB}_{\mathrm{diff}}$ over $4 \mathrm{~h}$ of dialysis with a fixed ultrafiltration rate. Our derivation of $\mathrm{IMB}_{\text {diff }}$ would appear to be a reasonable approach to gain some further insight into the effects of dialysate sodium concentration on sodium mass balance. $\mathrm{IMB}_{\text {diff }}$ was strongly correlated with both predialysis plasma conductivity and plasma sodium concentration. This is in keeping with previous experimental and theoretical data $[14,29]$. It has already been suggested that dialysate sodium concentration should be tailored to predialysis plasma sodium concentration in order to optimise diffusive removal $[27,30]$. It should be noted that the observed levels of correlation throughout our study were generally higher when plasma conductivity, rather than plasma sodium concentration, was considered. This may well be due to a relative lack of precision with respect to plasma sodium concentration measurement [31].
We also demonstrated negative $\mathrm{IMB}_{\text {diff }}$ (sodium loading) in only 3 out of 24 patients. The low proportion of patients with negative $\mathrm{IMB}_{\text {diff }}$ despite a dialysate sodium of $140 \mathrm{mmol} / \mathrm{l}$ is not surprising, as the patients had low levels of comorbidity, no diabetes and were not prone to intradialytic hypotension. Crucially, very few patients were hyponatraemic with only 4 patients having a predialysis plasma sodium of $<135 \mathrm{mmol} / \mathrm{l}$ (fig. 4), so there was a very low risk of negative $\mathrm{IMB}_{\text {diff. Moreover, we did not }}$ demonstrate an association between IMB and predialysis hypertension. We can speculate that a correlation would be masked by the use of antihypertensive medication in those patients with higher sodium loads. The relationship between sodium and BP in HD patients is more complicated than mere volume expansion. Previous models of sodium kinetics assume a two-compartment model, but Titze [17] has recently proposed an alternative threecompartment model by showing that sodium can accumulate in the vascular wall without volume expansion, which might explain the lag in improved BP control seen after dry weight reduction in patients treated with longslow HD [17, 32, 33].

There was a correlation between both diffusive and total IMB and IDWG $(\mathrm{r}=-0.57$ and -0.62 , respectively; $\mathrm{p}<0.01$ ). There was also a good correlation between the difference in plasma conductivity between the start and end of dialysis (fig. 3). This suggests a theoretically robust strategy to ensure an individualised isonatric dialysis treatment. Such an approach requires the relative contributions of convection with ultrafiltration and diffusion to be recognised and independently modulated. The removal of sodium with the ultrafiltration volume is, from a physician's point of view, a largely passive process. It is determined by the level of prescribed fluid removal and therefore does not offer an opportunity for independent tailoring of sodium removal. To ensure full and adequate removal of ingested sodium, it is necessary to know the amount of ingested sodium (and insensible loss \pm any effect of residual renal function). The difference between sodium ingested and sodium removed by (essentially hypotonic) ultrafiltrate would determine the degree of diffusive loss required (within the limits of cardiovascular tolerability). The ability to improve diffusive sodium removal by a lower end dialysis plasma conductivity might allow greater control over sodium balance, with the majority still due to ultrafiltration. This desired drop in plasma conductivity might be brought about by a variety of approaches. The ideal approach would be to directly prescribe a desired end dialysis plasma conductivity. This is possible by the use of a commercially available system 
(Diacontrol ${ }^{\circledR}$, Hospal). This system utilises software with sodium kinetic modelling to automatically control dialysate sodium conductivity in a biofeedback loop, to deliver a physician-prescribed end dialysis plasma conductivity. Such a system avoids continuous exposure to a persistently hypotonic dialysate [30]. Our previous study of the Diacontrol system did not show reduction in IDWG, and we attributed this to the fact that Diacontrol limits how low the desired end plasma conductivity and therefore effective sodium concentration can be set [34]. Recent work by Manlucu et al. [35] used the same Diacontrol system to achieve a stepwise reduction in postdialysis plasma conductivity from 14.0 to $13.5 \mathrm{mS} / \mathrm{cm}$. They showed an almost identical relationship between plasma conductivity and measured plasma sodium concentration as in the current study, whilst achieving a $98 \mathrm{mmol}$ increase in sodium removal estimated by IMB and a significant reduction in IDWG, BP and extracellular volume expressed as a percentage of total body water [35]. Not all centres have the availability of the Diacontrol system. In the absence of such a system, a similar result might be achieved by serial reduction in fixed dialysate sodium concentration, performed in combination with empirical observation of IMB and end plasma conductivity, until the desired reduction is achieved. The lack of intrapatient variability of both sodium removal and plasma sodium concentration suggests that such an approach might be feasible. De Paula et al. [36] propose that dialysate sodium be individualised according to the formula plasma $[\mathrm{Na}]$ $\times 0.95$, where $[\mathrm{Na}]$ is sodium concentration measured by indirect ion-selective electrode and based on a mean of 3 values. Such an approach led to improved IDWG and BP control in their study of 27 patients $[35,36]$.

The limitations of this study are that it is a small sample size and the conclusions may not be applicable to a dialysis population with greater comorbidity. Though this has previously been reported, we did not perform a validation of IMB as a measure of sodium mass balance by direct concentration measurement of the spent dialysate. Since conductivity monitoring cannot distinguish between ion types, this would have allowed us to quantify for the influence of the minor cations such as potassium, calcium and magnesium. Subsequently, the calculated sodium balance may be erroneous in individuals, particularly those with the highest predialysis potassium levels. The use of direct rather than indirect potentiometry for all plasma sodium concentration measurements would more directly reflect sodium activity and potentially reduce measurement errors. Another limitation is the use of a linear model for the time evolution of plasma conductivity (see online suppl. appendix 1), which allowed an estimate of the relative contributions of ultrafiltration and diffusion to sodium mass balance. A more sophisticated approach might be to derive an exponential function to account for the likely change in dialysate to plasma sodium gradient with time, which a larger sample size might allow.

In conclusion, the use of online conductivity monitoring to study sodium mass balance would appear to be both feasible and useful in individual patients. This study supports the notion that using a fixed rather than individualised dialysate sodium prescription leads to a wide range of sodium removal with potentially unrecognised sodium loading in patients, particularly those who are hyponatraemic. Online conductivity monitoring can be utilized as part of a variety of proposed strategies to enable the delivery of individualised and isonatric HD. Further study is required to explore the utility of such strategies, which may be crucial in reducing IDWG and HDinduced cardiac injury.

\section{References}

1 Villar E, Remontet L, Labeeuw M, Ecochard R, O'Brien AB: Effect of age, gender, and diabetes on excess death in end-stage renal failure. J Am Soc Nephrol 2007; 18:2125-2134.

-2 Kalantar-Zadeh K, Block G, Humphreys MH, Kopple JD: Reverse epidemiology of cardiovascular risk factors in maintenance dialysis patients. Kidney Int 2003;63:793808.

$\checkmark 3$ McIntyre CW: Effects of hemodialysis on cardiac function. Kidney Int 2009;76:371375 .
4 Gotch FA, Sargent JA: A mechanistic analysis of the National Cooperative Dialysis Study (NCDS). Kidney Int 1985;28:526-534.

5 Twardowski ZJ: Treatment time and ultrafiltration rate are more important in dialysis prescription than small molecule clearance. Blood Purif 2007;25:90-98

6 Tang HL, Wong SH, Chu KH, Lee W, Cheuk A, Tang CM, Kong IL, Fung KS, Tsang WK, Chan HW, Tong KL: Sodium ramping reduces hypotension and symptoms during haemodialysis. Hong Kong Med J 2006;12:1014
7 Davenport A: Audit of the effect of dialysate sodium concentration on inter-dialytic weight gains and blood pressure control in chronic haemodialysis patients. Nephron Clin Pract 2006;104:c120-c125.

$\checkmark 8$ Movilli E, Gaggia P, Zubani R, Camerini C, Vizzardi V, Parrinello G, Savoldi S, Fischer MS, Londrino F, Cancarini G: Association between high ultrafiltration rates and mortality in uraemic patients on regular haemodialysis. A 5-year prospective observational multicentre study. Nephrol Dial Transplant 2007;22:3547-3552. 
-9 Kalantar-Zadeh K, Regidor DL, Kovesdy CP, Van Wyck D, Bunnapradist S, Horwich TB, Fonarow GC: Fluid retention is associated with cardiovascular mortality in patients undergoing long-term hemodialysis. Circulation 2009;119:671-679.

-10 Kayikcioglu M, Tumuklu M, Ozkahya M, Ozdogan O, Asci G, Duman S, Toz H, Can LH, Basci A, Ok E: The benefit of salt restriction in the treatment of end-stage renal disease by haemodialysis. Nephrol Dial Transplant 2009;24:956-962.

11 Ozkaya M, Ok E, Cirit M, Aydin S, Akcicek F, Basci A, Mees E: Regression of left ventricular hypertrophy in haemodialysis patients by ultrafiltration and reduced salt intake without antihypertensive drugs. Nephrol Dial Transplant 1998;13:1489-1493.

-12 Burton JO, Jefferies HJ, Selby NM, McIntyre CW: Hemodialysis-induced cardiac injury: determinants and associated outcomes. Clin J Am Soc Nephrol 2009;4:914-920.

-13 Nguyen MK, Kurtz I: Quantitative interrelationship between Gibbs-Donnan equilibrium, osmolality of body fluid compartments, and plasma water sodium concentration. J Appl Physiol 2006;100:1293-1300.

14 Flanigan MJ: Role of sodium in hemodialysis. Kidney Int Suppl 2000;76:S72-S78.

$\checkmark 15$ Locatelli F, Salvatore D, Celestina M: Sodium kinetics during dialysis. Semin Dial 1999;12:S41-S44.

16 Funck-Brentano JL, Man NK: Optimization of $\mathrm{Na}$ content of dialysis fluid. Nephron 1984;36:197-200.

17 Titze J: Water-free sodium accumulation. Semin Dial 2009;22:253-255.

18 Worth HG: A comparison of the measurement of sodium and potassium by flame photometry and ion-selective electrode. Ann Clin Biochem 1985;22:343-350.
19 Mercadal L, Ridel C, Petitclerc T: Ionic dialysance: principle and review of its clinical relevance for quantification of hemodialysis efficiency. Hemodial Int 2005;9:111-119.

20 Moret K, Aalten J, van den Wall Bake W, Gerlag P, Beerenhout C, van der Sande F, Leunissen K, Kooman J: The effect of sodium profiling and feedback technologies on plasma conductivity and ionic mass balance: a study in hypotension-prone dialysis patients. Nephrol Dial Transplant 2006;21: 138-144.

21 Moret K, Hassell D, Kooman JP, van der Sande F, Gerlag PG, van den Wall Bake AW, van de Bogaart J, Leunissen KM: Ionic mass balance and blood volume preservation during a high, standard, and individualized dialysate sodium concentration. Nephrol Dial Transplant 2002;17:1463-1469.

22 Ramdeen G, Tzamaloukas AH, Malhotra D Leger A, Murata GH: Estimates of interdialytic sodium and water intake based on the balance principle: differences between nondiabetic and diabetic subjects on hemodialysis. ASAIO J 1998;44:812-817.

23 Polaschegg HD: Automatic, noninvasive intradialytic clearance measurement. Int J Ar tif Organs 1993;16:185-191.

24 Gotch FA, Lam MA, Prowitt M, Keen M: Preliminary clinical results with sodiumvolume modeling of hemodialysis therapy. Proc Clin Dial Transplant Forum 1980;10: 12-17.

25 Keen ML, Gotch FA: The association of the sodium 'setpoint' to interdialytic weight gain and blood pressure in hemodialysis patients. Int J Artif Organs 2007;30:971-979.

26 Peixoto AJ, Gowda N, Parikh CR: Long-term stability of serum sodium in hemodialysis patients. Blood Purif 2010;29:264-267.
27 Santos SFF, Peixoto AJ: Revisiting the dialysate sodium prescription as a tool for better blood pressure and interdialytic weight gain management in hemodialysis patients. Clin J Am Soc Nephrol 2008;3:522-530.

28 Mann H, Stiller S: Sodium modeling. Kidney Int Suppl 2000;76:S79-S88.

29 Locatelli F, Ponti R, Pedrini L, Costanzo R, Di Filippo S, Marai P, Pozzi C: Sodium kinetics across dialysis membranes. Nephron 1984;38:174-177.

30 Bosetto A, Bene B, Petitclerc T: Sodium management in dialysis by conductivity. Adv Ren Replace Ther 1999;6:243-254.

31 Santoro A, Mancini E, Paolini F, Cavicchioli G, Bosetto A, Zucchelli P: Blood volume regulation during hemodialysis. Am J Kidney Dis 1998;32:739-748.

-32 Charra B, Bergstrom J, Scribner BH: Blood pressure control in dialysis patients: importance of the lag phenomenon. Am J Kidney Dis 1998;32:720-724.

33 Simon G: Increased vascular wall sodium in hypertension: where is it, how does it get there and what does it do there? Clin Sci (Lond) 1990;78:533-540.

>34 Selby NM, Taal MW, McIntyre CW: Comparison of progressive conductivity reduction with diacontrol and standard dialysis. ASAIO J 2007;53:194-200.

>35 Manlucu J, Gallo K, Heidenheim PA, Lindsay RM: Lowering postdialysis plasma sodium (conductivity) to increase sodium removal in volume-expanded hemodialysis patients: a pilot study using a biofeedback software system. Am J Kidney Dis 2010;56:69-76.

36 de Paula FM, Peixoto AJ, Pinto LV, Dorigo D, Patricio PJ, Santos SF: Clinical consequences of an individualized dialysate sodium prescription in hemodialysis patients. Kidney Int 2004;66:1232-1238. 